\title{
Three-Dimensional Water-Based Magneto-Hydrodynamic Rotating Nanofluid Flow over a Linear Extending Sheet and Heat Transport Analysis: A Numerical Approach
}

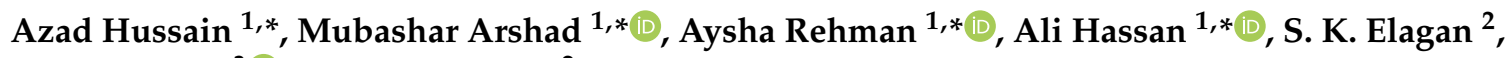 \\ Hijaz Ahmad ${ }^{3}$ and Amira Ishan ${ }^{2}$ \\ 1 Department of Mathematics, University of Gujrat, Gujrat 50700, Pakistan \\ 2 Department of Mathematics and Statistics, College of Science, Taif University, P.O. Box 11099, Taif 21944, \\ Saudi Arabia; skhali1@tu.edu.sa (S.K.E.); a.ishan@tu.edu.sa (A.I.) \\ 3 Section of Mathematics, International Telematic University Uninettuno, Corso Vittorio Emanuele II, 39, \\ 00186 Roma, Italy; hijaz555@gmail.com \\ * Correspondence: azad.hussain@uog.edu.pk (A.H.); imbashrii@gmail.com (M.A.); \\ aysharehman1986@gmail.com (A.R.); muhammadali0544@gmail.com (A.H.)
}

Citation: Hussain, A.; Arshad, M.; Rehman, A.; Hassan, A.; Elagan, S.K.; Ahmad, H.; Ishan, A.

Three-Dimensional Water-Based Magneto-Hydrodynamic Rotating Nanofluid Flow over a Linear Extending Sheet and Heat Transport Analysis: A Numerical Approach. Energies 2021, 14, 5133. https:// doi.org/10.3390/en14165133

Academic Editor:

Dharmendra Tripathi

Received: 20 July 2021

Accepted: 16 August 2021

Published: 19 August 2021

Publisher's Note: MDPI stays neutral with regard to jurisdictional claims in published maps and institutional affiliations.

Copyright: (c) 2021 by the authors. Licensee MDPI, Basel, Switzerland. This article is an open access article distributed under the terms and conditions of the Creative Commons Attribution (CC BY) license (https:/ / creativecommons.org/licenses/by/ $4.0 /)$.
Abstract: This comparative study inspects the heat transfer characteristics of magnetohydrodynamic (MHD) nanofluid flow. The model employed is a two-phase fluid flow model. Water is utilized as the base fluid, and zinc and titanium oxide $\left(\mathrm{Zn}\right.$ and $\left.\mathrm{TiO}_{2}\right)$ are used as two different types of nanoparticles. The rotation of nanofluid is considered along the $z$-axis, with velocity $\omega^{*}$. A similarity transformation is used to transform the leading structure of partial differential equations to ordinary differential equations. By using a powerful mathematical BVP-4C technique, numerical results are obtained. This study aims to describe the possessions of different constraints on temperature and velocity for rotating nanofluid with a magnetic effect. The outcomes for the rotating nanofluid flow and heat transference properties for both types of nanoparticles are highlighted with the help of graphs and tables. The impact of physical concentrations such as heat transference rates and coefficients of skin friction are examined. It is noted that rotation increases the heat flux and decreases skin friction. In this comparative study, Zn-water nanofluid was demonstrated to be a worthy heat transporter as compared to $\mathrm{TiO}_{2}$-water nanofluid.

Keywords: linear stretching surface; MHD; nanofluid; rotating flow; $\mathrm{Zn}$ and $\mathrm{TiO}_{2}$ as nanoparticles

\section{Introduction}

Problems of flow prompted by linear extending surfaces moving with definite velocity often occur in a large range of manufacturing processes. These types of flows have many applications in various assembling processes, such as extrusion of polymers from a dye, processing of foods, chemical fluids, etc. Crane [1] was the first to inspect the basic phenomenon of flow over the linear extending surface. After that, this area of research was found to be very interesting, and researchers began studying it under different physical constraints. Dandapat and Gupta [2] inspected the viscoelastic flow of fluid above the exponentially stretching surface. Zaimi et al. [3] and Hayat et al. [4] premeditated the rotating flow of viscid fluid and proved that frontier layer viscosity is an accumulative function of the viscid fluid parameter. Vajravelu and Kumar [5] conducted extraordinary research on the arithmetical and consistent clarification of a nonlinear system that proceeded from a three-dimensional rotating flow. Abbas and Magdy [6] studied to overcome the unsteady nanofluid magnetohydrodynamic flow through the permeable channel past the moving surface in the revolving device, taking into account heat and mass transfer. Conformational entropy in bio-convection nanofluid movement amongst two stretchable revolving disks was investigated by Khan et al. [7]. Nazar et al. [8] promoted unstable flow problems. Their outcomes specify a seamless alteration from the initial unstable flow to the end 
smooth-state flow. Hussain et al. [9,10] studied time-dependent compressible flow through the elliptical cylinder and engine oil base rotating nanofluid over a stretching sheet.

A nanoparticle is a small-sized particle that varies between 1 and $100 \mathrm{~nm}$ in size. When these nanosized particles are mixed in some base fluids such as water, engine oil, etc., the resulting mixture is known as a nanofluid. Nanofluids have many applications in engineering, agriculture, food processing, medical, and many other fields. Choi [11] was the leading researcher to introduce the concept of nanofluids. Nanofluids are used to enhance the thermal transmission of materials. During the last few decades, a popular research topic has been nanofluid convective heat transfer [12-16]. Nasirzadehroshenin et al. [17] demonstrated the temperature transmission of carbon nanotubes. Wang [18] studied viscid flow because of the linear stretching surface with surface suction and slipping conditions. Li and Zheng [19] generalized the heat transmission and thermal conductivity of nanofluids. Heat transference in viscous fluid above the extending sheet with heat generation and viscous dissipation was studied by Vajravelu and Hadjinicolaou [20]. Ibrahim et al. [21] deliberated on the thermal and hydraulic performance of helical heat exchangers filled with nanofluid. Lee et al. [22] measured the thermal conductivity containing oxide nanoparticles. Nima et al. [23] described an extraordinary study on the increasing role of nanofluids in many technological and bio-medical industries.

These days, magnetic fields are vastly applicable in many important industries. In refrigeration or warming applications, improving the heat, transmission is considered by the magnetic field. For this purpose, investigators introduced magnetic nanofluid. The MHD nanofluid plays an important role in biomedical imaging and many other applications. The important features of MHD nanofluid are discussed in this study under the magnetic effect. Thakhar and Nath [24] studied the unsteady rotating fluid flow above an extending surface in the existence of a magnetic field. Hussain et al. [25,26] enlightened on MHD hybrid nanofluid through the rotating cone and rotating flow on the exponentially stretching surface. Kumari and Nath [27] provided the analytical results of unsteady 3D magnetohydrodynamic (MHD) boundary layer flow and heat transmission. Afrand et al. [28,29] used a magnetic field to reduce the natural convection. Pak and Cho [30] presented heat transfer and hydrodynamic analysis of dispersed fluids with particles of metallic oxide. Waini et al. [31] studied heat transference and unstable flow above the extending surface for hybrid nanofluid. Hussain et al. [32] discussed MHD for viscid nanofluid with a radiative effect. Ahmed et al. [33] described the carbon nanotube magnetohydrodynamics nanofluid flow on a stretching surface. Currently, research is being conducted by Shafiq et al. [34] to describe the thermal slip and convective boundary slip in 3D flow. Hussain et al. [35] examined the carreau-yasuda temperature convention near a stagnation point. Rizwana et al. [36] studied the MHD oblique immobility point movement of nanofluids. For hybrid nanofluids, entropy generation and temperature-dependent viscidness are discussed by Ahmad et al. [37].

Shahid et al. [38] performed a numerical examination of stimulation energy on MHD nanofluid flow. Bahireal et al. [39] examined the manganese-zinc ferrite-water nanofluid under a non-uniform magnetic field. Waqas et al. [40] explored the MHD movement of hybrid nanofluids over the rotating disc with nonlinear thermal radiation and found good agreement in the results. Alsani et al. [41] deliberated on the joint effects of the inclined functional magnetic field, the absorbent stretching surface, the mass transportation, and the radiative warming on a micropolar flow. To the best of our knowledge, no one has described the joint effects of rotation and magnetic effect on water-based nanofluid above the stretching surface. Such types of flows may have possible applications, e.g., cooling of electronic chips, power plants, geothermal engineering, refineries, etc.

The primary goal of this research is to examine the heat transference characteristics and velocity of a rotating nanofluid above a $2 \mathrm{D}$ expanding surface numerically, in the presence of the magnetic effect. In this comparative study, $\mathrm{Zn}$-water and $\mathrm{TiO}_{2}$-water nanofluids are used due to both having many applications in industries. For example, Zn-water nanofluid is used for obtaining a better temperature transfer constant as compared to pure water 
base fluid. Similarly, $\mathrm{TiO}_{2}$-water nanofluid is used in the milk pasteurization industry as a heating fluid. The physical model utilized in this work is a two-phase nanofluid model to discuss the problem. The BVP-4C algorithm is used to obtain numerical results and graphs. Temperature, velocity, and skin friction coefficients are calculated, confirmed visually, and discussed concerning surface stretching ratio $\gamma$, magnetic parameter $M$, and rotation parameter $\lambda$.

\section{Statement of Problem}

Consider that a three-dimensional, MHD, viscous, and electrically conducting, rotating nanofluid, with constant density, lays atop a flat stretchy surface in the region $z>0$. The flow is persuaded by the stretching of the surface at $z=0$ along the $x$-axis and the $y$ axis, with rates $U_{w}=a x$ and $V_{w}=b y$ (see Figure 1), respectively. A constant magnetic field, $B_{0}$, is functionally perpendicular to the surface. For a reference related to the model, see [42]. $\mathrm{Zinc}(\mathrm{Zn})$ and titanium dioxide $\left(\mathrm{TiO}_{2}\right)$ nanoparticles with water $\left(\mathrm{H}_{2} \mathrm{O}\right)$ as the base fluid were considered for this study. The thermophysical characteristics of the water and nanoparticles are shown below in Table 1.

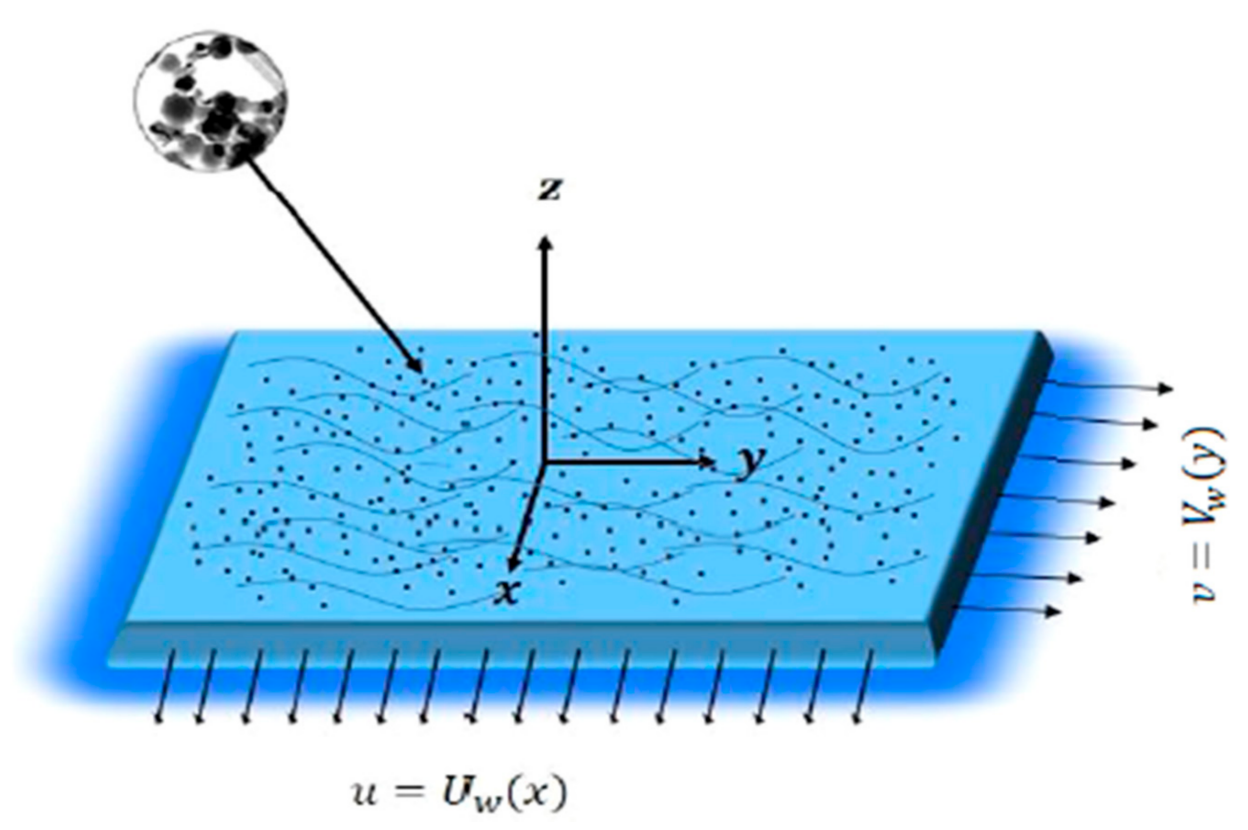

Figure 1. Geometry of the problem.

Table 1. Thermo physical characteristics of nanoparticles $\left(\mathrm{Zn}, \mathrm{TiO}_{2}\right)$ and base fluid, $\mathrm{H}_{2} \mathrm{O}$.

\begin{tabular}{cccc}
\hline Properties & Density $(\boldsymbol{\rho})$ & Thermal Conductivity $(\boldsymbol{K})$ & Specific Heat $\left(\boldsymbol{C}_{\boldsymbol{p}}\right)$ \\
\hline $\mathrm{Zn}$ & 7140 & 120 & 389 \\
$\mathrm{TiO}_{2}$ & 4250 & 8.96 & 686.2 \\
$\mathrm{H}_{2} \mathrm{O}$ & 997 & 0.613 & 4179 \\
\hline
\end{tabular}

\section{Equations and Mathematical Expressions}

Nanofluid rotates around the vertical axis, with a fixed velocity, $\omega^{*}$. With these suppositions and standard boundary layer approximation, the governing equations are:

$$
\begin{gathered}
\frac{\partial u}{\partial x}+\frac{\partial v}{\partial y}+\frac{\partial w}{\partial z}=0 \\
u \frac{\partial u}{\partial x}+v \frac{\partial u}{\partial y}+w \frac{\partial u}{\partial z}=2 \omega^{*} v+\frac{\mu_{n f}}{\rho_{n f}} \frac{\partial^{2} u}{\partial z^{2}}-\frac{\sigma B_{o}^{2}}{\rho_{n f}} u
\end{gathered}
$$




$$
\begin{gathered}
u \frac{\partial v}{\partial x}+v \frac{\partial v}{\partial y}+w \frac{\partial v}{\partial z}=-2 w^{*} u+\frac{\mu_{n f}}{\rho_{n f}} \frac{\partial^{2} v}{\partial z^{2}}-\frac{\sigma B_{o}{ }^{2}}{\rho_{n f}} v, \\
u \frac{\partial T}{\partial x}+v \frac{\partial T}{\partial y}+w \frac{\partial T}{\partial z}=\alpha_{n f} \frac{\partial^{2} T}{\partial z^{2}} .
\end{gathered}
$$

where $u$ is the $x$ constituent, $v$ is the $y$ constituent, and $w$ is the $z$ constituent of velocity, $\omega^{*} . \mu_{n f}$ is the dynamic viscidness, $\rho_{n f}$ is the density, $\alpha_{n f}$ is the thermal diffusivity, $T$ is the temperature, $\left(\rho C_{p}\right)_{n f}$ is the volumetric heat capacity of the nanofluid, $\left(\rho C_{p}\right)_{f}$ is the volumetric heat capacity of the base fluid, and $\left(\rho C_{p}\right)_{s}$ is the volumetric heat capacity of nanoparticles. As seen below, all of these are connected to the nanoparticle volume fraction, $\varphi$ [43], of nanoparticles.

$$
\begin{gathered}
\rho_{n f}=\rho_{f}(1-\varphi)+\varphi \rho_{s}, \quad \mu_{n f}=\frac{\mu_{n}}{(1-\varphi)^{5 / 2}}, \quad \rho_{n f}=\rho_{f} \frac{k_{n f}}{\alpha_{n f}}, \\
\left(\rho C_{p}\right)_{n f}=\left(\rho C_{p}\right)_{f}(1-\varphi)+\varphi\left(\rho C_{p}\right)_{s^{\prime}} \\
\frac{k_{f}}{k_{n f}}=\frac{k_{s}+2 k_{f}+2 \varphi\left(k_{f}-k_{s}\right)}{k_{s}+2 k_{f}-2 \varphi\left(k_{f}-k_{s}\right)}
\end{gathered}
$$

where $k_{f}$ represents the thermal transmission of the base fluid, $k_{s}$ represents the thermal transmission of nanoparticles, $\rho_{s}$ is the density of nanoparticles, and $\rho_{f}$ is the density of the base fluid.

The conforming boundary settings are provided below:

$$
\begin{gathered}
u=U_{w}=a x, v=V_{w}=b y, w=0, T=T_{w} \quad \text { as } z=0 . \\
u \rightarrow 0, v \rightarrow 0, T \rightarrow T_{\infty} \quad \text { as } z \rightarrow \infty .
\end{gathered}
$$

\subsection{Methodology of Transformation}

By applying the similarity transformations [44] listed below, i.e.,

$$
\begin{gathered}
u=\operatorname{axp}^{\prime}(\eta), v=a y q^{\prime}(\eta), w=-\sqrt{a v_{f}}\left[p^{\prime}(\eta)+q^{\prime}(\eta)\right], \\
\eta=z \sqrt{\frac{a}{v_{f}}}, r(\eta)=\frac{T-T_{\infty}}{T_{w}-T_{\infty}} .
\end{gathered}
$$

where $T_{w}$ and $T_{\infty}$ are the temperatures at the wall and free streams respectively, and $\eta$ is the dimensionless space parameter.

Subsequently, the overhead leading problem reduces to:

$$
\begin{aligned}
\frac{1}{(1-\varphi)^{5 / 2}} p^{\prime \prime \prime} & (\eta) \\
& =\left(1-\varphi+\varphi \frac{\rho_{s}}{\rho_{b f}}\right)\left[p^{\prime 2}(\eta)\right. \\
& \left.-p^{\prime \prime}(\eta)\{p(\eta)+q(\eta)\}-2 \lambda \delta q^{\prime}(\eta)\right]+p^{\prime}(\eta) M^{2}, \\
\frac{1}{(1-\varphi)^{5 / 2} q^{\prime \prime \prime}} & (\eta) \\
& =\left(1-\varphi+\varphi \frac{\rho_{s}}{\rho_{b f}}\right)\left[q^{\prime 2}(\eta)\right. \\
& \left.-q^{\prime \prime}(\eta)\{p(\eta)+q(\eta)\}-2 \frac{\lambda}{\delta} q^{\prime}(\eta)\right]+q^{\prime}(\eta) M^{2}, \\
\frac{k_{n f}}{k_{f}} r^{\prime \prime}(\eta)+\operatorname{Pr} & {\left[1-\varphi+\varphi \frac{\left(\rho C_{p}\right)_{s}}{\left(\rho C_{p}\right)_{f}}\right]\left[r^{\prime}(\eta)\{p(\eta)+q(\eta)\}\right]=0 }
\end{aligned}
$$

with the following boundary conditions:

$$
p=0, \quad p^{\prime}=1, \quad q=0, \quad q^{\prime}=\gamma, \quad r=1 \quad \text { as } \eta=0
$$




$$
p^{\prime} \rightarrow 0, \quad q^{\prime} \rightarrow 0, \quad r \rightarrow 0 \quad \text { as } \eta \rightarrow \infty
$$

where $\left(\rho C_{p}\right)_{f}$ is the volumetric temperature capability of the base fluid and $\left(\rho C_{p}\right)_{s}$ is the volumetric temperature capability of nanoparticles.

In Equations (9)-(11), $\lambda$ is the rotation parameter, $\gamma$ is the surface extension ratio, $M$ is the magnetic constraint, and $P r$ is the Prandtl number, and they are defined as:

$$
\lambda=\frac{\omega^{*}}{a}, \quad M=\sqrt{\frac{\sigma \beta 0^{2}}{a \rho_{f}}}, \quad \gamma=\frac{b}{a}, \quad \operatorname{Pr}=\frac{\left(\mu C_{p}\right)_{f}}{k_{f}} .
$$

\subsection{Solution Methodology}

The joint structure of ordinary differential Equations (8)-(10) is highly nonlinear, and it has been numerically addressed. The BVP-4C technique converts the leading differential equations into a structure of first-order ordinary differential equations that are easy to handle and solved repeatedly. MATLAB has been used to generate numerical tables and graphical results.

The physical extents of the distinct comforts are skin frictions $\left(C_{f x}, C_{f y}\right)$ along the $x$ and $y$-axis, respectively, and Nusselt number, $N u_{x}$, where

$$
C_{f x}=\frac{\tau_{x z}}{\rho_{f}(a x)^{2}}, \quad C_{f y}=\frac{\tau_{y z}}{\rho_{f}(a x)^{2}}, \quad N u_{x}=\frac{x q_{w}}{k_{f}\left(T-T_{\infty}\right)}
$$

where $\tau_{x z}$ and $\tau_{y z}$ are wall shear pressures and $q_{w}$ is heat fluctuation, given by:

$$
\tau_{x z}=\mu_{n f}\left(\frac{\partial u}{\partial z}\right)_{z=0} \tau_{y z}=\mu_{n f}\left(\frac{\partial v}{\partial z}\right)_{z=0^{\prime}} q_{w}=-k_{n f}\left(\frac{\partial T}{\partial z}\right)_{z=0}
$$

By using Equations (8) and (15) in Equation (14), the above physical extents are written in dimensionless form as:

$$
\begin{gathered}
\operatorname{Re}^{\frac{1}{2}} C_{f x}=\frac{1}{(1-\phi)^{\frac{5}{2}}} p^{\prime \prime}(0), \quad \operatorname{Re}^{\frac{1}{2}} C_{f y}=\frac{1}{(1-\phi)^{\frac{5}{2}}} q^{\prime \prime}(0), \\
(R e)^{-1 / 2} N u_{x}=\frac{-k_{n f}}{k_{f}} r^{\prime}(0)
\end{gathered}
$$

where local Reynolds number is $R e_{x}=\frac{(a x)_{x}}{v_{f}}$. Skin friction $\frac{1}{(1-\phi)^{5 / 2}} p^{\prime \prime}(0)$ and heat flux $\frac{-k_{n f}}{k_{f}} r^{\prime}(0)$ are calculated for both types of nanofluid with different values of parameters.

\section{Results and Discussion}

The impact of numerous somatic factors such as rotation, $\lambda$, magnetic, $M$, and surface stretching ratio, $\gamma$, constraints on temperature and velocity profiles for $\mathrm{Zn}$-water as well as $\mathrm{TiO}_{2}$-water nanofluids are discussed in this section. The volume fraction concentration of solid nanoparticles $\left(\mathrm{Zn}\right.$ and $\left.\mathrm{TiO}_{2}\right)$ has been set to $\varphi=0.1$ throughout the study for analysis. To elaborate on the occurring influence of these distinguished study parameters on different outcomes, graphical results have been plotted to physically demonstrate changes happening in respective outcomes under a certain study parameter. The tabulated datasets for both sets of nanofluids were generated under distinct study parameters, for the local skin friction coefficient and the heat transfer coefficient. The Nusselt number coefficient of the present study has been found in good agreement with previously published results.

Figure 2a,b schemed to identify the impact on velocity profile $p^{\prime}(\eta)$ and $q^{\prime}(\eta)$ (along the $x$ - and $y$-axis, respectively) of the Magnetic constraint, $M$, for both types of nanofluid, respectively. By increasing the magnetic constraint, $M$, it can be perceived from Figure 2a,b that there was a boost in deceleration for both types of nanofluid. The existence of a transverse magnetic field produces the Lorentz force, which is an opposing force that opposes the smooth motion of the fluid. Therefore, by raising the magnetic field parameter, 
the Lorentz force rises and results in a decrement of velocity and the related thermal boundary layer of fluid in $x$ and $y$ directions.

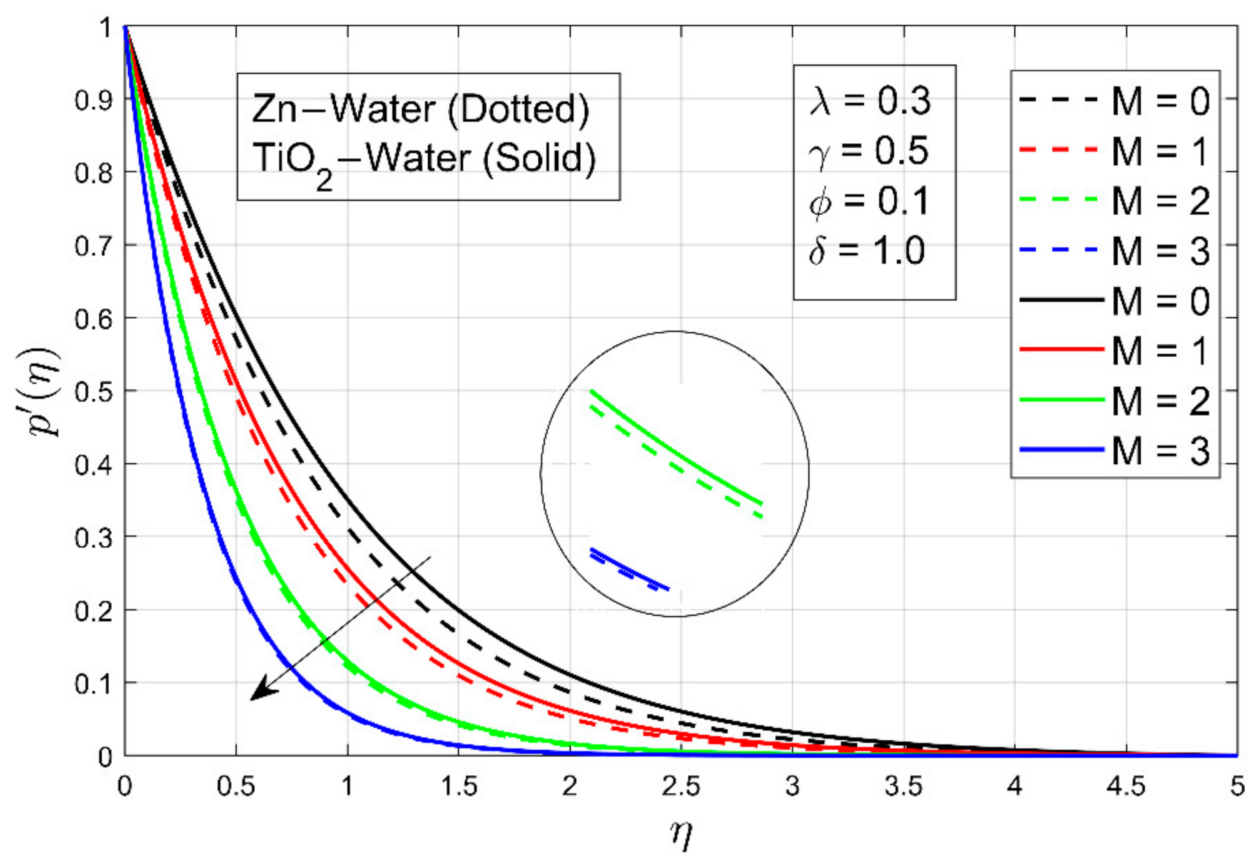

(a)

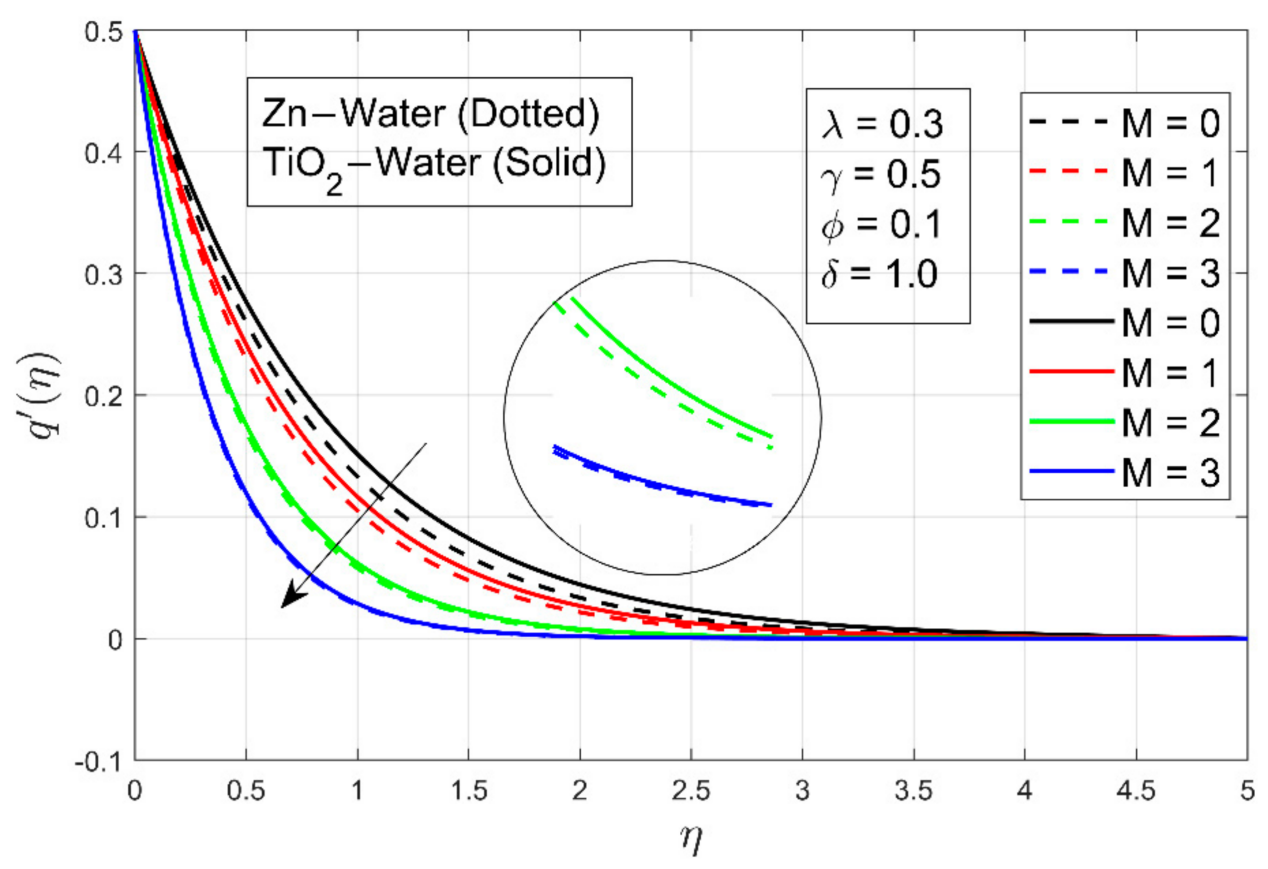

(b)

Figure 2. (a) The influence of $M$ on $p^{\prime}(\eta)$, and (b) the influence of $M$ on $q^{\prime}(\eta)$.

Moreover, the stimulus of rotation, $\lambda$, on velocity constituents $p^{\prime}(\eta)$ and $q^{\prime}(\eta)$ is presented in Figure 3a,b. From Figure 3a,b, it is clear that the velocity profiles $\left(p^{\prime}(\eta), q^{\prime}(\eta)\right)$ and boundary layer thickness decay as the rotation parameter, $\lambda$, increases. These figures also show that the velocity of the $\mathrm{Zn}$-water nanofluid is always smaller than $\mathrm{TiO}_{2}$ because 
of the lower density of titanium oxide nanoparticles that can move easily as compared to zinc nanoparticles, since they are comparatively heavier in density.

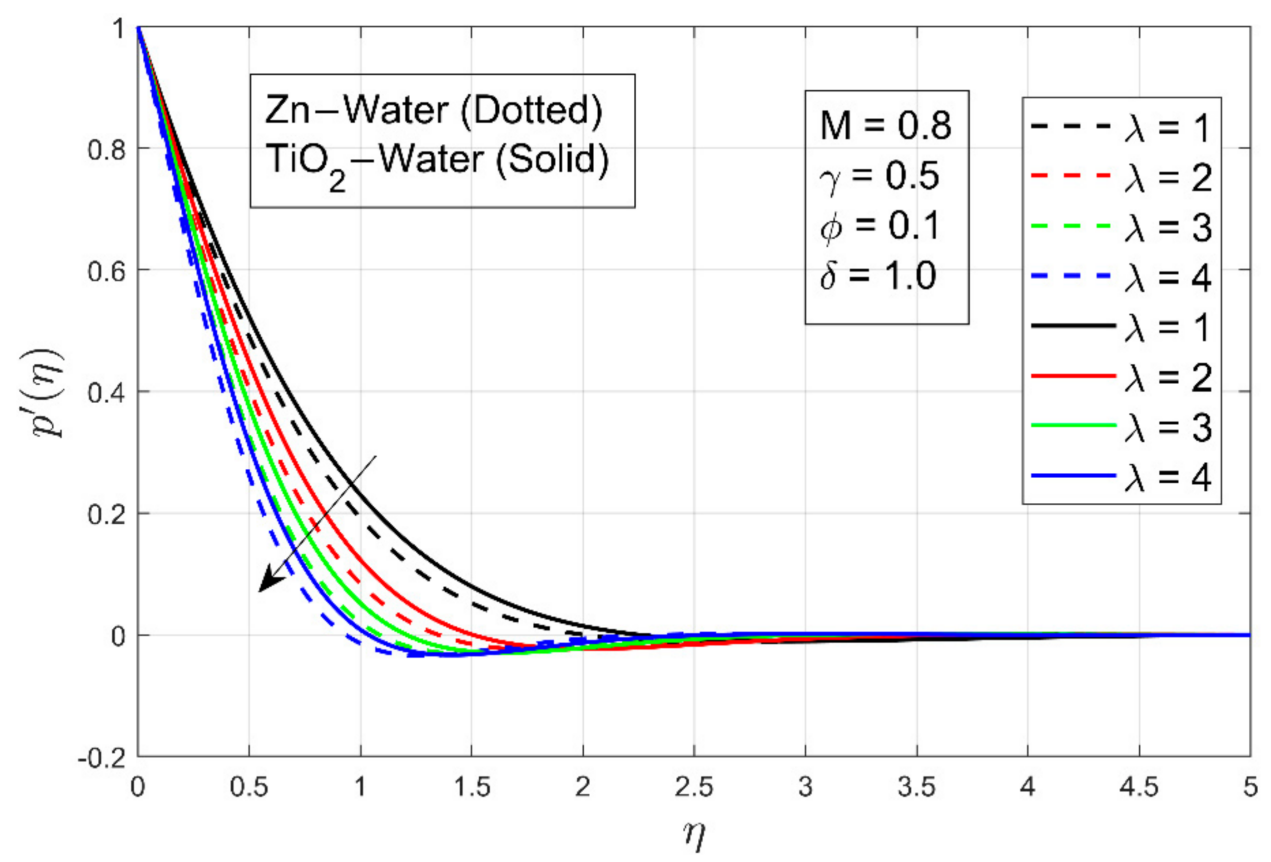

(a)

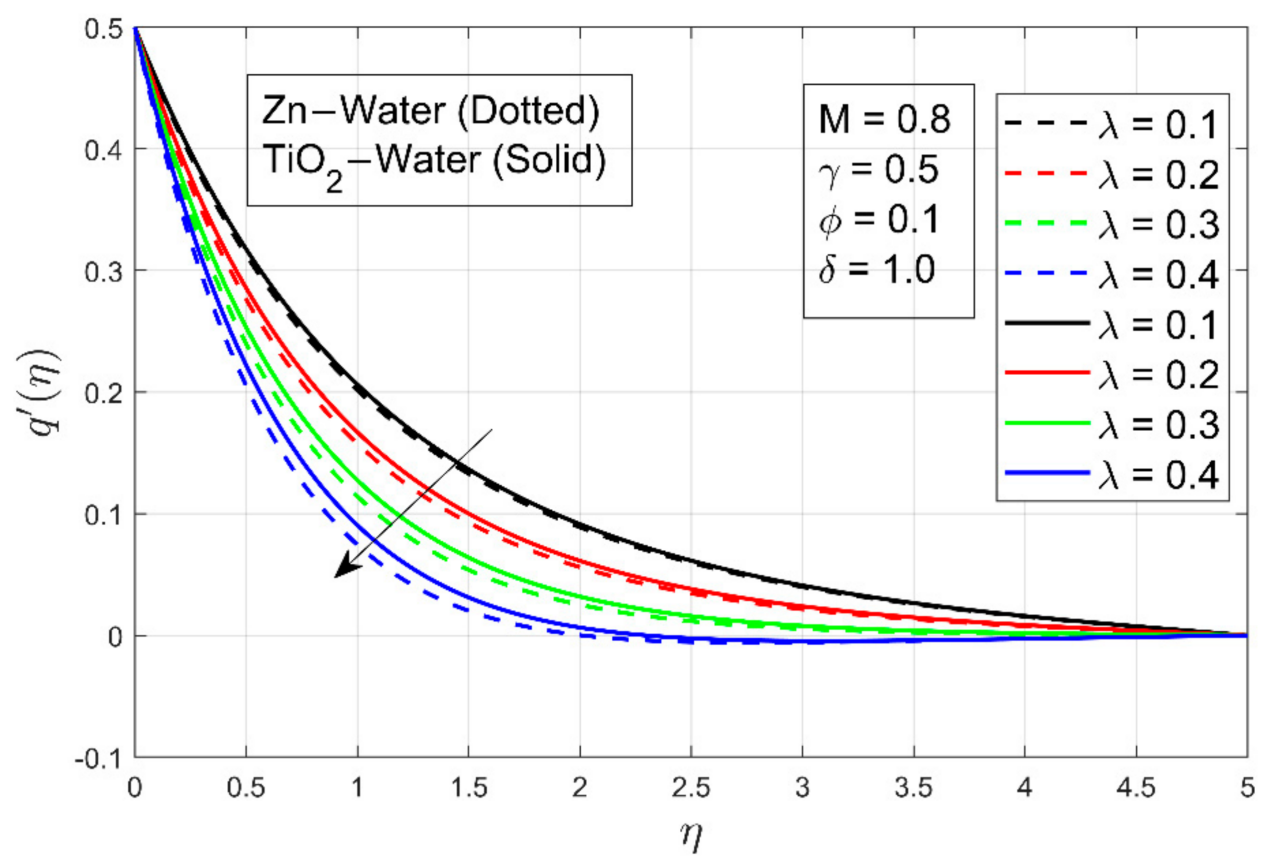

(b)

Figure 3. (a) The influence of rotation, $\lambda$, on $p^{\prime}(\eta)$, and (b) the influence of rotation, $\lambda$, on $q^{\prime}(\eta)$.

Figure $4 \mathrm{a}$, b show the impact of stretching ratio parameter, $\gamma$, on $p^{\prime}(\eta)$ and $q^{\prime}(\eta)$. Physically, along the $y$-axis, as the rate of stretching ratio parameter $\gamma$ increases, there is an increment in the rate of enlarging $a$, which infers an upsurge in velocity and thickness of the momentum boundary layer. The influence of stretching ratio in Figure $4 a, b$ shows a very distinct pattern, as under high increasing stretching ratio, Figure 4a shows a very 
dense behavior. This shows that the thermal boundary layer has decreased significantly along with primary velocity, and the reason for this particular phenomenon is the presence of a strong resistive Lorentz force. Figure $4 \mathrm{~b}$ shows the opposite behavior as compared to Figure 4a. This depicts that thermal boundary increases even under the presence of a high magnetic field.

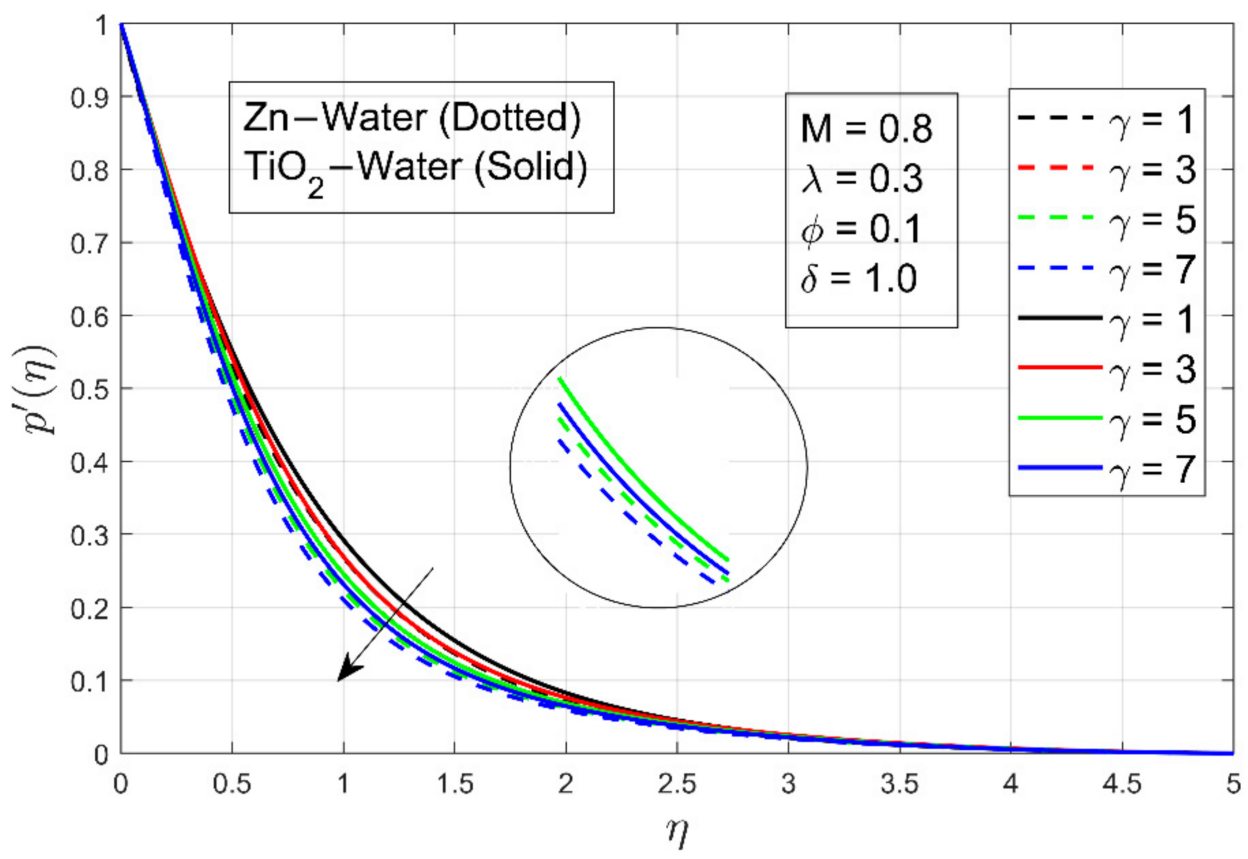

(a)

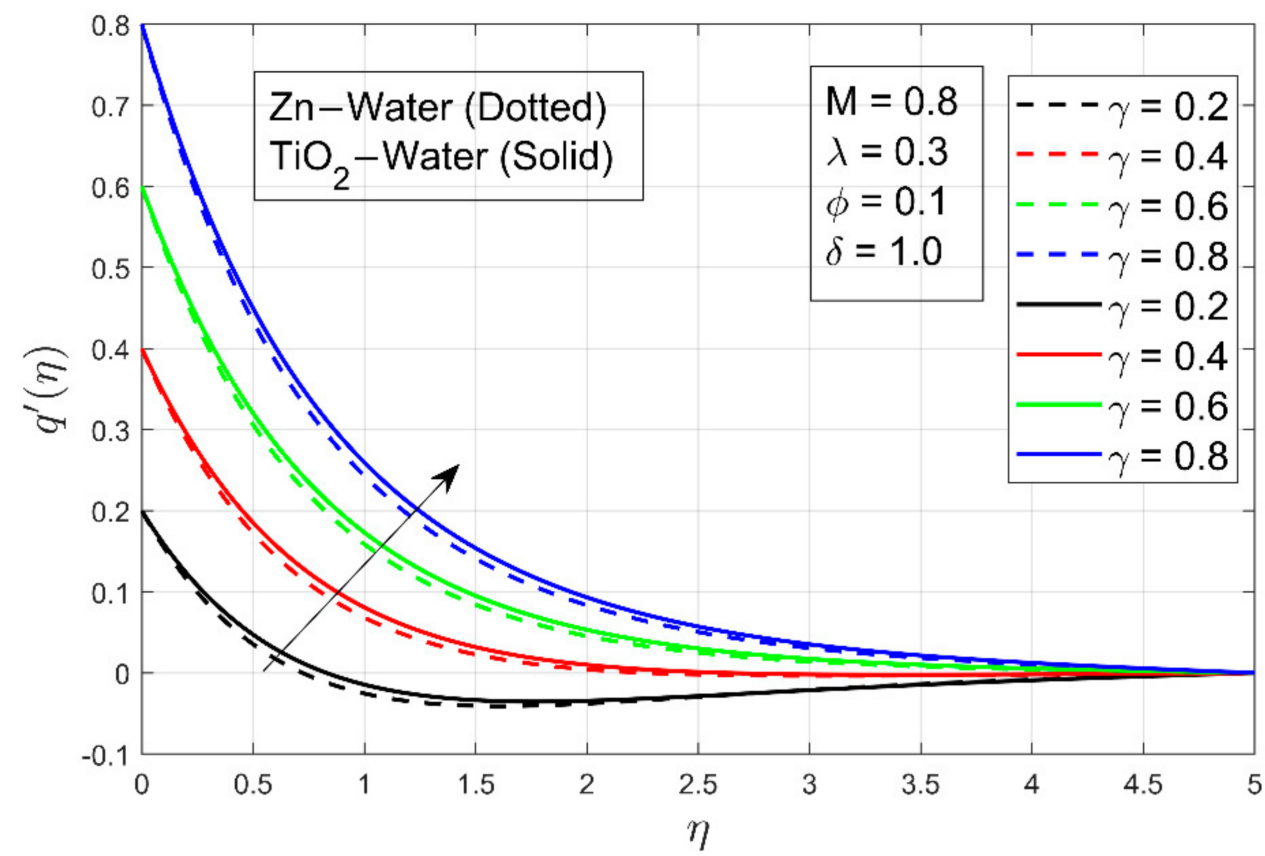

(b)

Figure 4. (a) The influence of $\gamma$ on $p^{\prime}(\eta)$, and (b) the influence of $\gamma$ on $q^{\prime}(\eta)$.

A distinction in temperature profile, $r(\eta)$, against the magnetic parameter, $M$, is shown in Figure 5a. We can determine from Figure $5 \mathrm{a}$ that the rise in magnetic constraint, $M$, 
results in a decrease in temperature profile, $r(\eta)$, and the linked thickness of the boundary layer. Figure $5 \mathrm{~b}$ indicates the effects of rotation constraint, $\lambda$, on the temperature field. It can be noticed that rotation boosts the boundary layer thickness. Furthermore, an instant decrease in temperature was observed. The influence of the stretching ratio constraint, $\gamma$, on the heat coefficient can be seen in Figure $5 c$. The temperature distribution as well as the thermal boundary layer are receding functions of $\gamma$ in this illustration. The behavior of the temperature profile under the different study parameters $M, \lambda$, and $\gamma$, can be observed from Figure 5a-c. Although the temperature is decreasing gradually under the increasing magnetic field, rotation, and stretching ratio, under the increasing stretching ratio parameter, the maximum boundary layer of fluid is found, as in Figure 5c.

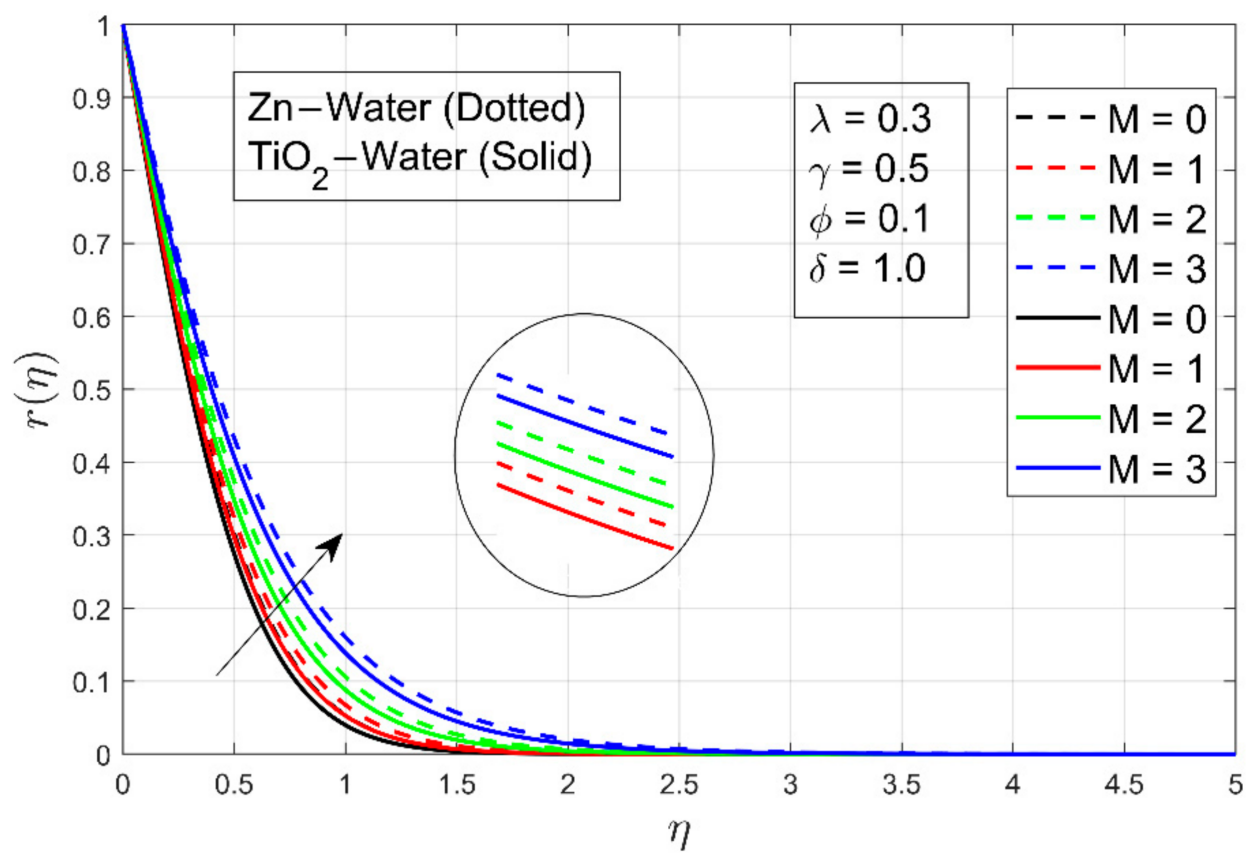

(a)

Figure 5. Cont. 


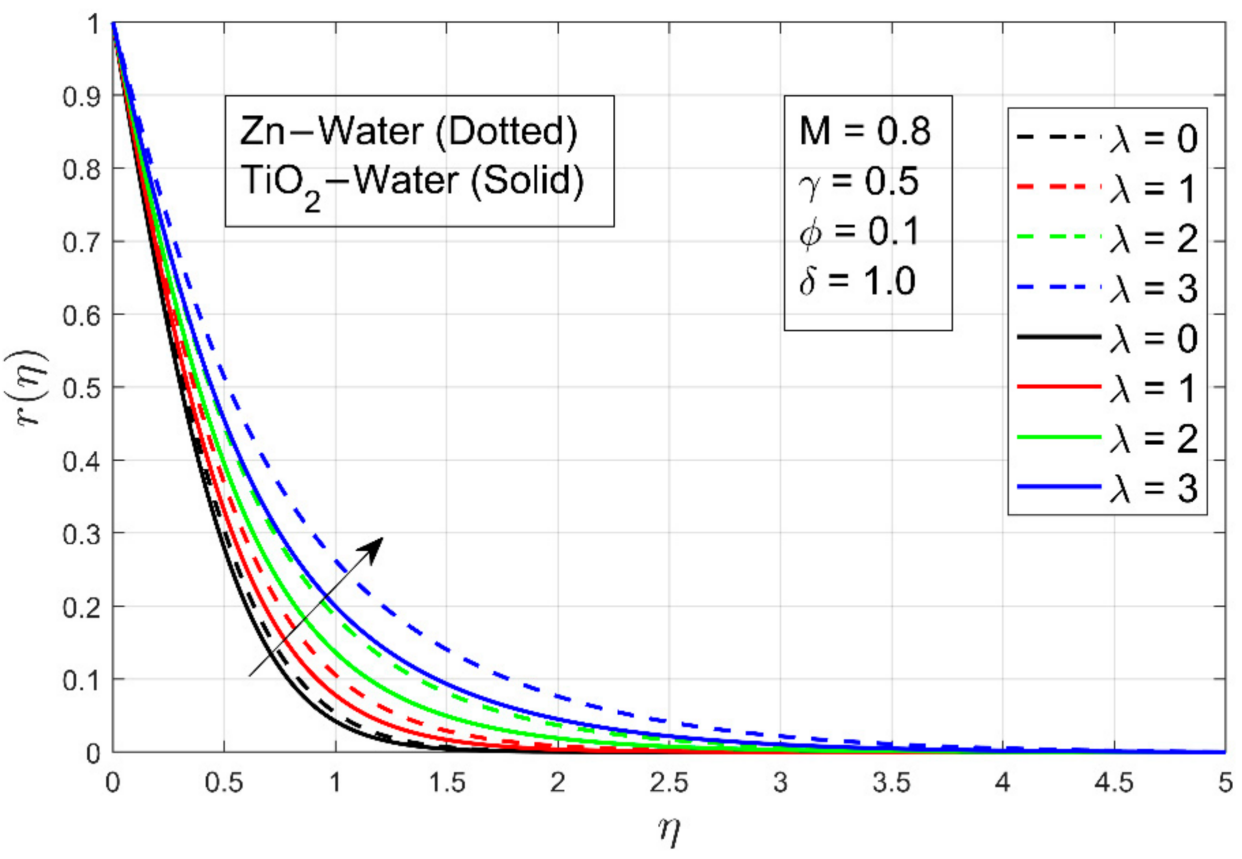

(b)

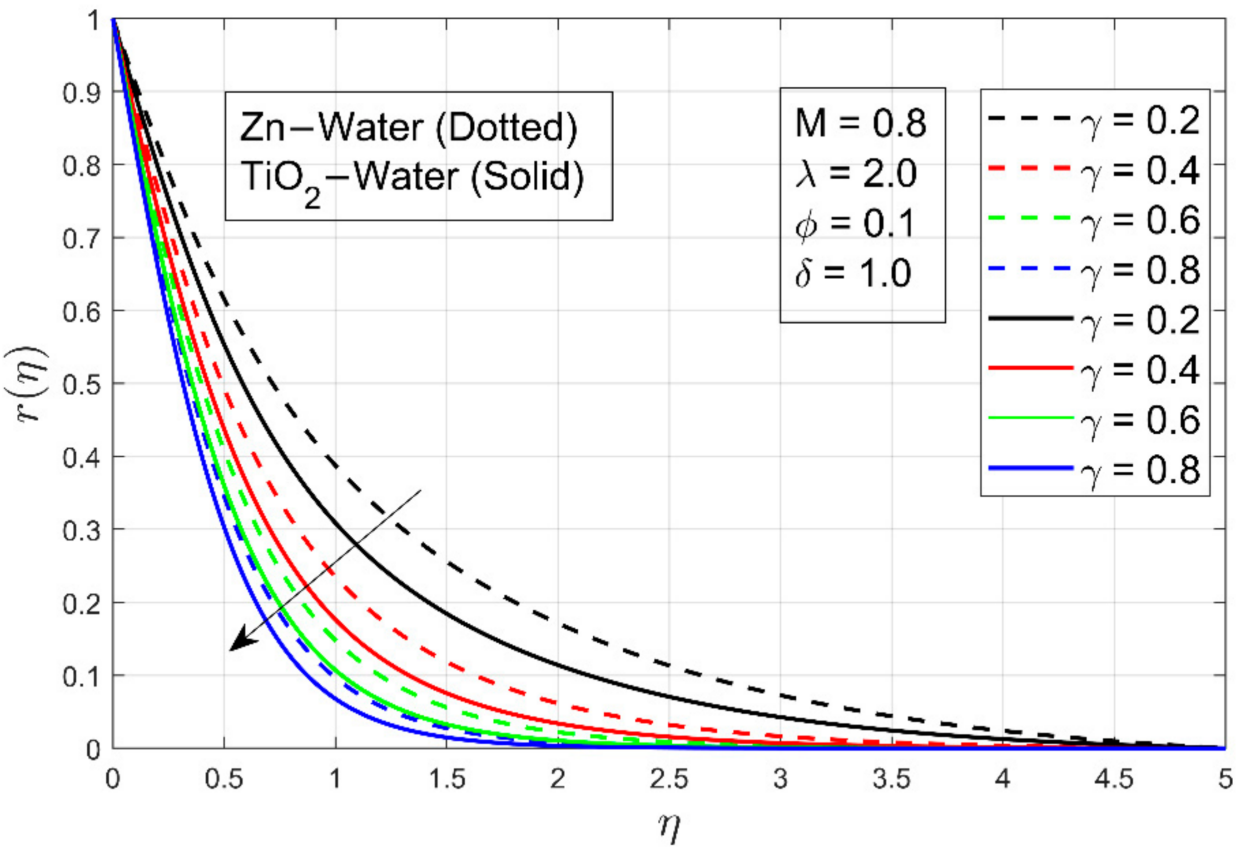

(c)

Figure 5. (a) The influence of $M$ on $r(\eta)$, (b) the influence of $\lambda$ on $r(\eta)$, and (c) the influence of $\gamma$ on $r(\eta)$.

The accompanying figures and tables are designed to examine the impacts of interesting physical constraints on the skin friction coefficient and Nusselt number. Table 2 was prepared to measure the precision of the present outcomes, which are compared with already available works. Tables 3 and 4 present the numerical results. Figure $6 a, b$ shows that by increasing the rotation parameter, $\lambda$, with a non-zero constant stretching ratio constraint, $\gamma$, and increasing the magnetic constraint, $M$, it is observed that, in the 
$x$-direction, a normal pressure in the tangential direction increases to a specific value, but in the $y$-direction, similar tangential stress decreases. Whereas Figure $6 \mathrm{c}$ shows that Zn-water nanofluid has a high Nusselt number, as compared to other nanofluids. The Zn-water nanofluid case provides us with suitable results for the heat transfer coefficient under certain increasing study parameters, and it can be seen from Table 3 that as the fluid rotation is increased, the maximum Nusselt number is observed. Table 4 shows the Nusselt number results for the $\mathrm{TiO}_{2}$-water case, which are comparatively low under the influence of the study parameter as compared to the $\mathrm{Zn}$-water case.

Table 2. For specific situations, the present results are compared to prior research.

\begin{tabular}{ccccccc}
\hline \multirow{2}{*}{$\lambda$} & \multicolumn{2}{c}{ Current Outcomes } & \multicolumn{2}{c}{ Wang [45] } & \multicolumn{2}{c}{ Nazar et al. [8] } \\
\cline { 2 - 6 } & $\boldsymbol{p}^{\prime \prime}(\mathbf{0})$ & $\boldsymbol{q}^{\prime} \mathbf{( 0 )}$ & $\boldsymbol{p}^{\prime \prime}(\mathbf{0})$ & $\boldsymbol{q}^{\prime} \mathbf{( 0 )}$ & $\boldsymbol{p}^{\prime \prime}(\mathbf{0})$ & $\boldsymbol{q}^{\prime} \mathbf{( 0 )}$ \\
\hline 0 & -1.0042 & 0 & -1 & 0 & -1 & 0 \\
0.5 & -1.1718 & -0.5488 & -1.13 & -0.51 & -1.13 & -0.51 \\
1.0 & -1.358 & -0.8589 & -1.32 & -0.83 & -1.32 & -0.83 \\
2.0 & -1.6803 & -1.3027 & -1.65 & -1.28 & -1.65 & -1.28 \\
\hline
\end{tabular}

Table 3. Impacts of different constraints on skin friction $\left(\mathrm{Cf}_{\mathrm{x}}, \mathrm{Cf}_{\mathrm{y}}\right)$ and Nusselt number $(\mathrm{Nu})$ for $\mathrm{Zn}$-water nanofluid for $\operatorname{Pr}=6.2, \varphi=0.1$, and $\delta=1.0$.

\begin{tabular}{cccccc}
\hline$\gamma$ & $\lambda$ & $M$ & $\frac{\mathbf{1}}{(\mathbf{1}-\boldsymbol{\phi})^{5 / 2}} \boldsymbol{p}^{\prime \prime}(\mathbf{0})$ & $\frac{\mathbf{1}}{(\mathbf{1}-\boldsymbol{\phi})^{5 / 2}} \boldsymbol{q}^{\prime \prime}(\mathbf{0})$ & $\frac{-\boldsymbol{k}_{\text {nf }}}{k_{f}} \boldsymbol{r}^{\prime}(\mathbf{0})$ \\
\hline 0.1 & 0.3 & 0.8 & -1.54562 & -1.56269 & 2.97912 \\
0.2 & & & -1.41984 & -3.96466 & 3.67241 \\
0.3 & & -1.36439 & -8.75791 & 4.14194 \\
0.4 & & & -1.33724 & -16.4982 & 4.48949 \\
0.5 & 0.1 & 0.8 & -1.56349 & -1.87907 & 2.27043 \\
& 0.2 & & -1.65041 & -2.82227 & 1.96687 \\
& 0.3 & & -1.77573 & -3.54611 & 1.71304 \\
0.5 & 0.4 & & -1.90465 & -4.15217 & 1.51723 \\
& 0.1 & 0.0 & -1.50594 & -0.382448 & 2.61189 \\
& & 0.1 & -1.89001 & -0.720246 & 2.48536 \\
& & 0.2 & -2.73174 & -1.23201 & 2.25914 \\
& & 0.3 & -2.25914 & -1.77523 & 2.01437 \\
\hline
\end{tabular}

Table 4. Impacts of different constraints on skin friction $\left(\mathrm{Cf}_{\mathrm{x}}, \mathrm{Cf}_{\mathrm{y}}\right)$ and Nusselt number $(\mathrm{Nu})$ for $\mathrm{TiO}_{2}$-water nanofluid for $\operatorname{Pr}=6.2, \varphi=0.1$, and $\delta=1.0$.

\begin{tabular}{cccccc}
\hline$\gamma$ & $\lambda$ & $\boldsymbol{M}$ & $\frac{\mathbf{1}}{(\mathbf{1}-\boldsymbol{\phi})^{\mathbf{5 / 2}}} \boldsymbol{p}^{\prime \prime}(\mathbf{0})$ & $\frac{\mathbf{1}}{(\mathbf{1}-\boldsymbol{\phi})^{\mathbf{5 / 2}}} \boldsymbol{q}^{\prime \prime} \mathbf{( 0 )}$ & $\frac{-\boldsymbol{k}_{\mathbf{n f}}}{\boldsymbol{k}_{f}^{\prime}} \boldsymbol{r}^{\mathbf{0})}$ \\
\hline 0.1 & 0.3 & 0.8 & -1.45376 & -1.46874 & 2.92044 \\
0.2 & & & -1.34304 & -3.67532 & 3.60029 \\
0.3 & & -1.29282 & -8.02293 & 4.07366 \\
0.4 & & -1.26807 & -15.0339 & 4.43019 \\
0.5 & 0.1 & 0.8 & -1.45396 & -1.70304 & 2.28394 \\
& 0.2 & & -1.52366 & -2.55282 & 2.04226 \\
& 0.3 & & -1.63243 & -3.20773 & 1.82357 \\
0.5 & 0.4 & & -1.74623 & -3.75668 & 1.64007 \\
& 0.1 & 0.0 & -1.36727 & -0.351682 & 2.56409 \\
& & 0.1 & -1.77874 & -0.698189 & 2.44193 \\
& & 0.2 & -2.65633 & -1.21686 & 2.22396 \\
& & 0.3 & -3.68213 & -1.76417 & 1.98899 \\
\hline
\end{tabular}




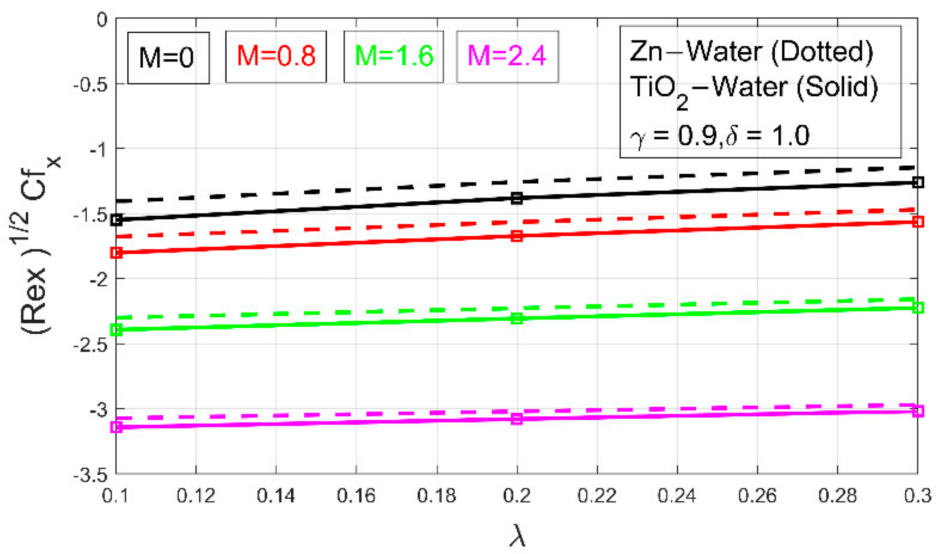

(a)

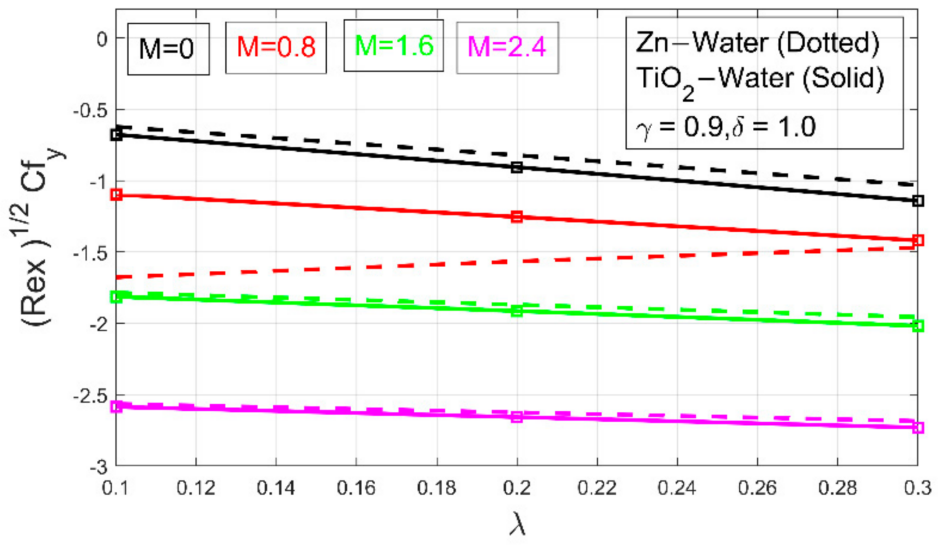

(b)

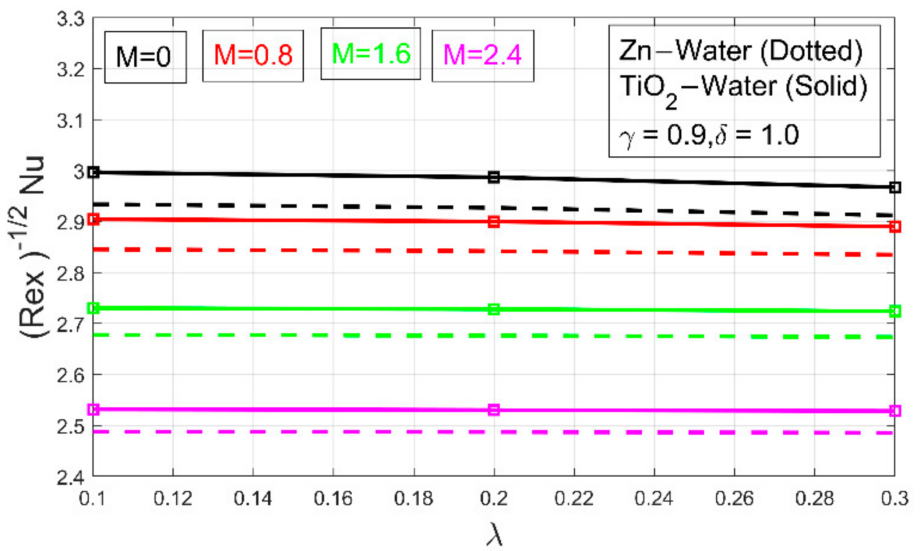

(c)

Figure 6. (a) Skin friction along the $x$-axis, (b) skin friction along the $y$-axis, and (c) Nusselt number. 


\section{Conclusions}

In this research, a numerical investigation was implemented on MHD, three-dimensional flow above the stretching surface/sheet. Two nanofluid combinations were considered in order to observe and compare the enhanced heat transfer and reduction in skin friction for both cases. The BVP-4C technique was used to tackle the problem. Via similarity transformation, the arising partial differential equations were converted to ordinary differential equations through a newly defined set of variables. The numerical results have been numerically validated with previously published work. Further deductions can be made as follows:

1. Increasing the magnetic parameter, $M$, resulted in decreasing the temperature transfer rate for both nanofluids;

2. As magnetic, $M$, and rotation, $\lambda$, parameters were increased, the velocity of both nanofluids dropped;

3. As the rotation, $\lambda$, parameter increased, the decay rate of skin friction and a rise in heat flux for both types of nanofluids increased;

4. An increase in the temperature profile because of the magnetic parameter, $M$, was found to be less conspicuous for $\mathrm{TiO}_{2}$-water as compared to $\mathrm{Zn}$-water nanofluid;

5. An increase in surface stretching ratio, $\gamma$, decreased the temperature of nanofluids;

6. The study found that the $\mathrm{Zn}$-water nanofluid has high rates of heat transfer as compared to the other considered nanofluid, $\mathrm{TiO}_{2}$-water.

Author Contributions: Conceptualization, A.H. (Azad Hussain) and M.A.; methodology, A.R.; software, M.A.; validation, S.K.E., H.A. and A.I.; formal analysis, A.R.; investigation, A.R., A.H. (Ali Hassan); resources, M.A.; data curation, H.A.; writing-original draft preparation, M.A., writingreview and editing, A.H. (Ali Hassan); visualization, S.K.E. and A.I.; supervision, A.H. (Azad Hussaian); project administration, H.A.; funding acquisition, A.I. All authors have read and agreed to the published version of the manuscript.

Funding: This work is supported by Taif University Researchers Supporting Project number (TURSP2020/223), Taif University, Taif, Saudi Arabia.

Data Availability Statement: The data presented in this study are available on request from the corresponding authors.

Conflicts of Interest: The authors have no conflict of interest.

\section{Nomenclature}

$\boldsymbol{a}, \boldsymbol{b} \quad$ Stretching rates of surface

$C f_{x}, C f_{y} \quad$ Skin friction alongside $x$-axis and $y$-axis

$C_{p} \quad$ Specific heat capacity

$\rho C_{p} \quad$ Volumetric heat capacity

$k \quad$ Thermal conductivity

$M \quad$ Magnetic parameter

$\gamma \quad$ Surface stretching ratio parameter

$\lambda \quad$ Rotation parameter

$N u_{x} \quad$ Nusselt number

Pr Prandtl number

Re Reynold number

$\mathrm{T} \quad$ Temperature of fluid

$T_{w} \quad$ Temperature at wall

$T_{\infty} \quad$ The temperature outside the surface

$\boldsymbol{u}, \boldsymbol{v}, \boldsymbol{w} \quad$ Velocity constituents of $x-, y-$, and $z$-axis, respectively

$\boldsymbol{\alpha}_{n f} \quad$ Thermal diffusivity of nanofluid

$v_{n f} \quad$ Kinematics viscosity of nanofluid

$\rho_{n f} \quad$ Density of nanofluid 


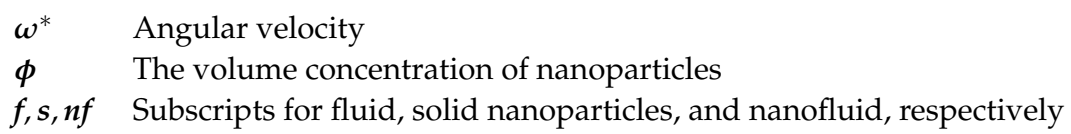

\section{References}

1. Crane, L.J. Flow past a stretching plate. Z. Angew. Math. Phys. 1970, 21, 645-647. [CrossRef]

2. Dandapat, B.; Gupta, A. Flow and heat transfer in a viscoelastic fluid over a stretching sheet. Int. J. Non-Linear Mech. 1989, 24, 215-219. [CrossRef]

3. Zaimi, K.; Ishak, A.; Pop, I. Stretching surface in rotating viscoelastic fluid. Appl. Math. Mech. 2013, 34, 945-952. [CrossRef]

4. Hayat, T.; Farooq, M.; Alsaedi, A.; Al-Solamy, F. Impact of Cattaneo-Christov heat flux in the flow over a stretching sheet with variable thickness. AIP Adv. 2015, 5, 087159. [CrossRef]

5. Vajravelu, K.; Kumar, B. Analytical and numerical solutions of a coupled non-linear system arising in a three-dimensional rotating flow. Int. J. Non-Linear Mech. 2004, 39, 13-24. [CrossRef]

6. Abbas, W.; Magdy, M.M. Heat and Mass Transfer Analysis of Nanofluid Flow Based on, and over a Moving Rotating Plate and Impact of Various Nanoparticle Shapes. Math. Prob. Eng. 2020, 2020, 9606382. [CrossRef]

7. Khan, N.S.; Shah, Q.; Bhaumik, A.; Kumam, P.; Thounthong, P.; Amiri, I. Entropy generation in bioconvec-tion nanofluid flow between two stretchable rotating disks. Sci. Rep. 2020, 10, 1-26.

8. Nazar, R.; Amin, N.; Pop, I. Unsteady boundary layer flow due to a stretching surface in a rotating fluid. Mech. Res. Commun. 2004, 31, 121-128. [CrossRef]

9. Hussain, A.; Hassan, A.; Al Mdallal, Q.; Ahmad, H.; Rehman, A.; Altanji, M.; Arshad, M. Heat transporta-tion enrichment and elliptic cylindrical solution of time-dependent flow. Case Stud. Therm. Eng. 2021, 27, 101248. [CrossRef]

10. Hussain, A.; Arshad, M.; Rehman, A.; Hassan, A.; Elagan, S.K.; Alshehri, N.A. Heat Transmission of Engine-Oil-Based Rotating Nanofluids Flow with Influence of Partial Slip Condition: A Computational Model. Energies 2021, 14, 3859. [CrossRef]

11. Choi, S.U.; Eastman, J.A. Enhancing Thermal Conductivity of Fluids with Nanoparticles; No. ANL/MSD/CP-84938; CONF-951135-29; Argonne National Laboratory: Lemont, IL, USA, 1995.

12. Ganvir, R.; Walke, P.; Kriplani, V. Heat transfer characteristics in nanofluid-A review. Renew. Sustain. Energy Rev. 2017, 75, 451-460. [CrossRef]

13. Cheng, L. Nanofluid Heat Transfer Technologies. Recent Pat. Eng. 2009, 3, 1-7. [CrossRef]

14. Xuan, Y.; Li, Q. Heat transfer enhancement of nanofluids. Int. J. Heat Fluid Flow 2000, 21, 58-64. [CrossRef]

15. Sheikholeslami, M.; Bhatti, M. Active method for nanofluid heat transfer enhancement by means of EHD. Int. J. Heat Mass Transf. 2017, 109, 115-122. [CrossRef]

16. Akbari, M.; Galanis, N.; Behzadmehr, A. Comparative analysis of single and two-phase models for CFD studies of nanofluid heat transfer. Int. J. Therm. Sci. 2011, 50, 1343-1354. [CrossRef]

17. Nasirzadehroshenin, F.; Sadeghzadeh, M.; Khadang, A.; Maddah, H.; Ahmadi, M.H.; Sakhaeinia, H.; Chen, L. Modeling of heat transfer performance of carbon nanotube nanofluid in a tube with fixed wall temperature by using ANN-GA. Eur. Phys. J. Plus 2020, 135, 217. [CrossRef]

18. Wang, C. Analysis of viscous flow due to a stretching sheet with surface slip and suction. Nonlinear Anal. Real World Appl. 2009, 10, 375-380. [CrossRef]

19. Li, B.; Zheng, L.; Zhang, X. Heat transfer in pseudo-plastic non-Newtonian fluids with variable thermal conductivity. Energy Convers. Manag. 2011, 52, 355-358. [CrossRef]

20. Vajravelu, K.; Hadjinicolaou, A. Heat transfer in a viscous fluid over a stretching sheet with viscous dissipation and internal heat generation. Int. Commun. Heat Mass Transf. 1993, 20, 417-430. [CrossRef]

21. Ibrahim, M.; Algehyne, E.A.; Saeed, T.; Berrouk, A.S.; Chu, Y.M.; Cheraghian, G. Assessment of economic, thermal and hydraulic performances a corrugated helical heat exchanger filled with non-Newtonian nanofluid. Sci. Rep. 2021, 11, 1-16. [CrossRef]

22. Lee, S.; Choi, S.S.; Li, S.A.; Eastman, J.A. Measuring thermal conductivity of fluids containing oxide nanoparticles. J. Heat Transf. 1999, 121, 280-289. [CrossRef]

23. Nima, Z.A.; Biswas, A.; Bayer, I.S.; Hardcastle, F.D.; Perry, D.; Ghosh, A.; Biris, A.S. Applications of sur-face-enhanced Raman scattering in advanced bio-medical technologies and diagnostics. Drug Metab. Rev. 2014, 46, 155-175. [CrossRef]

24. Takhar, H.S.; Nath, G. Unsteady flow over a stretching surface with a magnetic field in a rotating fluid. Z. Angew. Math. Phys. 1998, 49, 989-1001. [CrossRef]

25. Hussain, A.; Hassan, A.; Al Mdallal, Q.; Ahmad, H.; Rehman, A.; Altanji, M.; Arshad, M. Heat transport investigation of magneto-hydrodynamics (SWCNT-MWCNT) hybrid nanofluid under the thermal radiation regime. Case Stud. Therm. Eng. 2021, 27, 101244. [CrossRef]

26. Hussain, A.; Alshbool, M.H.; Abdussattar, A.; Rehman, A.; Ahmad, H.; Nofal, T.A.; Khan, M.R. A computational model for hybrid nanofluid flow on a rotating surface in the existence of convective condition. Case Stud. Therm. Eng. 2021, $27,101089$.

27. Kumari, M.; Nath, G. Analytical solution of unsteady three-dimensional MHD boundary layer flow and heat transfer due to impulsively stretched plane surface. Commun. Nonlinear Sci. Numer. Simul. 2009, 14, 3339-3350. [CrossRef]

28. Afrand, M. Using a magnetic field to reduce natural convection in a vertical cylindrical annulus. Int. J. Therm. Sci. 2017, 118, 12-23. [CrossRef] 
29. Afrand, M.; Farahat, S.; Nezhad, A.H.; Sheikhzadeh, G.A.; Sarhaddi, F.; Wongwises, S. Multi-objective optimization of natural convection in a cylindrical annulus mold under magnetic field using particle swarm algorithm. Int. Commun. Heat Mass Transf. 2015, 60, 13-20. [CrossRef]

30. Pak, B.C.; Cho, Y.I. Hydrodynamic and heat transfer study of dispersed fluids with Submicron metallic oxide particles. Exp. Heat Transf. 1998, 11, 151-170. [CrossRef]

31. Waini, I.; Ishak, A.; Pop, I. Unsteady flow and heat transfer past a stretching/shrinking sheet in a hybrid nanofluid. Int. J. Heat Mass Transf. 2019, 136, 288-297. [CrossRef]

32. Hussain, A.; Sarwar, L.; Akbar, S.; Malik, M.Y.; Ghafoor, S. Model for MHD viscoelastic nanofluid flow with prominence effects of radiation. Heat Transf. Asian Res. 2019, 48, 463-482. [CrossRef]

33. Ahmed, Z.; Nadeem, S.; Saleem, S.; Ellahi, R. Numerical study of unsteady flow and heat transfer CNT-based MHD nanofluid with variable viscosity over a permeable shrinking surface. Int. J. Numer. Methods Heat Fluid Flow 2019, 29, 4607-4623. [CrossRef]

34. Shafiq, A.; Rasool, G.; Khalique, C.M. Significance of Thermal Slip and Convective Boundary Conditions in Three Dimensional Rotating Darcy-Forchheimer Nanofluid Flow. Symmetry 2020, 12, 741. [CrossRef]

35. Hussain, A.; Rehman, A.; Nadeem, S.; Malik, M.Y.; Issakhov, A.; Sarwar, L.; Hussain, S. A combined convection carreau-yasuda nanofluid model over a convective heated surface near a stagnation point: A numerical study. Math. Probl. Eng. 2021. [CrossRef]

36. Rizwana, R.; Hussain, A.; Nadeem, S. Mix convection non- boundary layer flow of unsteady MHD oblique stagnation point flow of nanofluid. Int. Commun. Heat Mass Transf. 2021, 124, 105285. [CrossRef]

37. Ahmad, S.; Nadeem, S.; Ullah, N. Entropy generation and temperature-dependent viscosity in the study of SWCNT-MWCNT hybrid nanofluid. Appl. Nanosci. 2020, 10, 5107-5119. [CrossRef]

38. Shahid, A.; Huang, H.L.; Khalique, C.M.; Bhatti, M.M. Numerical analysis of activation energy on MHD nanofluid flow with exponential temperature-dependent viscosity past a porous plate. J. Therm. Anal. Calorim. 2021, 143, 2585-2596. [CrossRef]

39. Bahiraei, M.; Hosseinalipour, S.M.; Hangi, M. Numerical study and optimization of hydrothermal characteristics of Mn-Zn ferrite nanofluid within annulus in the presence of magnetic field. J. Superconduct. Novel Magn. 2014, 27, 527-534. [CrossRef]

40. Waqas, H.; Farooq, U.; Naseem, R.; Hussain, S.; Alghamdi, M. Impact of MHD radiative flow of hybrid nanofluid over a rotating disk. Case Stud. Therm. Eng. 2021, 26, 101015. [CrossRef]

41. Aslani, K.-E.; Mahabaleshwar, U.S.; Singh, J.; Sarris, I.E. Combined Effect of Radiation and Inclined MHD Flow of a Micropolar Fluid Over a Porous Stretching/Shrinking Sheet with Mass Transpiration. Int. J. Appl. Comput. Math. 2021, 7, 1-21. [CrossRef]

42. Hayat, T.; Nadeem, S.; Khan, A.U. Rotating flow of Ag-CuO/H2O hybrid nanofluid with radiation and partial slip boundary effects. Eur. Phys. J. E 2018, 41, 1-9. [CrossRef] [PubMed]

43. Nadeem, S.; Rehman, A.; Mehmood, R.; Sadiq, M. Partial Slip Effects on a Rotating Flow of Two Phase Nano Fluid Over a Stretching Surface. Curr. Nanosci. 2014, 10, 846-854. [CrossRef]

44. Hayat, T.; Nadeem, S. An improvement in heat transfer for rotating flow of hybrid nanofluid: A numerical study. Can. J. Phys. 2018, 96, 1420-1430. [CrossRef]

45. Wang, C.Y. Stretching a surface in a rotating fluid. Z. Angew. Math. Phys. 1988, 39, 177-185. [CrossRef] 